\title{
Functional Trimeric SARS-CoV-2 Envelope Protein Expressed in Stable CHO Cells
}

\author{
Patrick Mayrhofer, Monika Hunjadi and Renate Kunert* \\ Department of Biotechnology, Institute of Animal Cell Technology and Systems Biology, University of Natural Resources and Life \\ Sciences (BOKU), Vienna, Austria
}

The severe acute respiratory syndrome coronavirus 2 (SARS-CoV-2), a $\beta$-coronavirus, is the causative agent of the COVID-19 pandemic. One of the three membrane-bound envelope proteins is the spike protein (S), the one responsible for docking to the cellular surface protein ACE2 enabling infection with SARS-CoV-2. Although the structure of the S-protein has distinct similarities to other viral envelope proteins, robust and straightforward protocols for recombinant expression and purification are not described in the literature. Therefore, most studies are done with truncated versions of the protein, like the receptor-binding domain. To learn more about the interaction of the virus with the ACE2 and other cell surface proteins, it is mandatory to provide recombinant spike protein in high structural quality and adequate quantity. Additional mutant variants will give new insights on virus assembly, infection mechanism, and therapeutic drug development. Here, we describe the development of a recombinant $\mathrm{CHO}$ cell line stably expressing the extracellular domain of a trimeric variant of the SARS CoV-2 spike protein and discuss significant parameters to be considered during the expression and purification process.

Concordia University, Canada

Muralikannan Maruthamuthu,

University of North Carolina at Chapel

Hill, United States

Keywords: SARS-CoV-2, COVID-19, spike (S) glycoprotein, CR3022, pandemic, envelope protein, perfusion, integrated bioprocessing

${ }^{*}$ Correspondence:

Renate Kunert

renate.kunert@boku.ac.at

\section{INTRODUCTION}

Specialty section:

This article was submitted to

Synthetic Biology,

a section of the journal

Frontiers in Bioengineering and

Biotechnology

Received: 18 September 2021

Accepted: 15 November 2021

Published: 17 December 2021

Citation:

Mayrhofer $P$, Hunjadi $M$ and Kunert $R$ (2021) Functional Trimeric SARS-CoV-

2 Envelope Protein Expressed in Stable

$\mathrm{CHO}$ Cells.

Front. Bioeng. Biotechnol. 9:779359.

doi: 10.3389/fbioe.2021.779359

In late 2019, the human population was hit by a novel beta-coronavirus outbreak that challenged the different healthcare systems around the globe. Biotechnological progress of recent decades enabled rapid identification and characterization of the causative agent of this emerging infectious disease and to develop molecular and immunological tests and effective vaccines based on structural features of SARS-CoV-2 (Xiong et al., 2020; Davidson et al., 2021). One key feature of this zoonotic virus is the extracellular domain of the homotrimeric envelop spike protein that mediates attachment and entry into lung epithelial cells upon binding to its receptor, the angiotensin-converting enzyme 2 (ACE2) (Huang et al., 2020; Shang et al., 2020). The spike protein is a highly complex glycoprotein with more than 22 potential $\mathrm{N}$-glycosylation sites, 15 disulfide bonds and forms a homotrimeric structure protruding from the viral surface (Tian et al., 2021). A suitable method for rapid production of proteins for further method development is transient gene expression (TGE). However, mass production using TGE is limited in terms of cheap and efficient gene transfer reagents and high-quality plasmid DNA (Kam et al., 2007; Li et al., 2013; Kirchdoerfer et al., 2018; Chun et al., 2019; Tortorici et al., 2019; Bangaru et al., 2020; Cai et al., 2020; Esposito et al., 2020; Hsieh et al., 2020; Stadlbauer et al., 2020; Xiong et al., 2020; Budge et al., 2021; Castro et al., 2021; 
Herrera et al., 2021; Schaub et al., 2021). Furthermore, uptake of multiple plasmid copies and extrachromosomal expression in the producer cells lead to cellular stress conditions, and the culture supernatant is usually harvested at suboptimal viability to improve product yield. Consequently, the downstream purification process is more challenging due to the poor product quality and higher amounts of impurities. In contrast, stable cell lines maintain the expression capacity over extended population doubling times and are independent of the culture scale, making them an attractive option for large-scale manufacturing of this complex protein (Allen et al., 2021; Cibelli et al., 2021; Johari et al., 2021). In order to express the spike protein independent from the viral environment, an engineered version of the extracellular part of the S-protein was designed (Genbank QJE37812.1), and the genetic construct was obtained from the laboratory of Prof. Krammer at the Mount Sinai School of Medicine at the beginning of the pandemic (Amanat et al., 2020). In this "chimeric spike soluble" (CSs) protein, two mutations were introduced to stabilize the structure of the protein: K986P and V987P at a helix-turn-helix motif to retain the S2 in the prefusion conformation and thereby disfavor the refolding due to restricted backbone torsion angles. Previous studies demonstrated that proline substitutions in the loop between the first heptad repeat (HR1) and the central helix restrict premature triggering of the fusion protein and often increase expression yields of prefusion ectodomains. The rearrangements of class I fusion proteins are a key step in the transition to the post-fusion conformation. In order to prevent the cleavage between S1 and S2 by furin, the polybasic cleavage site was modified (Wrapp et al., 2020), which makes the modified, recombinant SARS CoV-2 spike protein (CSs) also more similar to the SARS-CoV and the MERS $\mathrm{S}$-protein. At the C-terminus, a chimeric foldon domain of the T4 phage was added to promote trimerization of the molecule (Meier et al., 2004). These modifications resulted in a stabilized version of the extracellular domain of the SARS CoV-2 S-protein and were designed according to the first reported genome sequence of 2019-nCoV (Wu et al., 2020), positions $1-1,208$. The structure of this recombinant S-protein was analyzed in electron microscopy (Wrapp et al., 2020).

We demonstrate a workflow that started early in the pandemic using existing cell culture platforms established in the research group to rapidly and efficiently produce recombinant cell lines of the soluble version of the trimeric spike protein in high yield. Analytical methods to quantify and evaluate the quality of this critical protein are highlighted and were developed early to support the entire cell line development. Finally, highly efficient bioprocesses, based on shake tubes or lab-scale bioreactors cultivated in perfusion and traditional fed-batch mode followed by a primary affinity capture step using immobilized metal affinity chromatography (IMAC), are presented. Final harvest titers could be increased by a factor of 10 using a hypothermic temperature shift in bioreactor fed-batch cultures. The presented IMAC purification elution profile was optimized for purity and quality rather than yield, which is diligently presented in other studies (Johari et al., 2021). The produced spike protein showed characteristic binding to antiSARS mAb CR3022 and polyclonal immunoglobulins isolated from hyperimmunoglobulin preparations. Furthermore, the spike protein was successfully applied in serological ELISA.

\section{MATERIALS AND METHODS SARS-CoV-2 Chimeric Spike Soluble Protein}

The recombinant chimeric spike soluble (CSs) protein (Genbank QJE37812.1, Amanat et al., 2020) comprises the Sars-CoV-2 S1/S2 spike protein with two stabilizing proline mutations (K986P, V987P) and a mutation of the polybasic cleavage site (RRAR) together with a thrombin cleavage site. The chimeric foldon domain of the T4 phage was added at the C-terminus of the protein to promote trimerization of the molecule (Meier et al., 2004) followed by a 6x His tag. The mature CSs monomeric chain, thus, consists of 1,242 amino acids, 30 cysteine residues, and 22 potential $\mathrm{N}$-glycosylation sites. The calculated molecular weight of the monomeric CSs chain is $180 \mathrm{kDa}$, assuming $2.5 \mathrm{kDa}$ per glycosylation site. Similarly, a theoretical molecular weight of $540 \mathrm{kDa}$ is calculated for the full trimeric CSs spike protein. Amino acid sequence information is presented.

\section{The Expression Vector and Cloning Strategy} The original plasmid pCAGGS-CSs (Amanat et al., 2020) was received from Prof. Krammer at the Mount Sinai Medical School (New York City, NY, USA) and was co-transfected with pCIneo (Promega) that harbors the G418 selection marker. For stable cell line generation, the open reading frame of CSs was cloned into the AscI-linearized $\mathrm{pL}$ mammalian expression vector (Mader et al., 2012; Zboray et al., 2015), resulting in pL-CSs. The backbone of $\mathrm{pL}$ includes a chimeric CAGGS promoter (CMV enhancer, chicken beta-actin promoter, chimeric intron of chicken betaactin and rabbit beta-globin), bovine growth hormone (bGH) poly(A) signal, phosphoglycerate kinase promoter driving expression of the neomycin phosphotransferase gene (NeoR/ KanR) for G418 resistance, a bacterial origin of replication (ori), bacterial ampicillin resistance gene (AmpR) and a $5^{\prime}$ and $3^{\prime}$ homology region $\left(5^{\prime} \mathrm{HR}\right.$ and $\left.3^{\prime} \mathrm{HR}\right)$ for potential recombination into bacterial artificial chromosomes (BACs).

A suspension $\mathrm{CHO}-\mathrm{K} 1$ cell line adapted to ActiPro medium (Cytiva) + $6 \mathrm{mM} \mathrm{L-gln}$ was chosen as the preferred host cell line for recombinant protein expression. It was previously demonstrated that this host cell line is particularly suitable for recombinant protein production (Reinhart et al., 2018). Alternatively, these cells can be cultivated in $\mathrm{CDCHO}$ medium (Gibco) without negatively impacting cellular growth. For transfection, $10 \mu \mathrm{g}$ of plasmid DNA was resuspended in $200 \mu \mathrm{l}$ of CD-DG44 medium (Gibco). Five micrograms of pCAGGS-CSs and $5 \mu \mathrm{g}$ of pCIneo were mixed and transfected to generate initial transfection pools and early protein production. Similarly, $10 \mu \mathrm{g}$ of pL-CSs was transfected for the establishment of monoclonal stable high-producing cell lines. Lipofectin, $50 \mu$ l, was mixed with $150 \mu$ of CD-DG44, incubated for $35 \mathrm{~min}$, then pooled with the 
plasmid solution and incubated for $10 \mathrm{~min}$. The Lipoplex solution was then added to $2 \times 10^{6}$ viable $\mathrm{CHO}-\mathrm{K} 1$ cells in $3.6 \mathrm{ml} \mathrm{CD}-\mathrm{DG} 44+8 \mathrm{mM}$ stable $\mathrm{L}-\mathrm{gln}+15 \mathrm{mg} / \mathrm{L}$ phenol red and incubated for $24 \mathrm{~h}$ at $220 \mathrm{rpm}$. At $24 \mathrm{~h}$ post-transfection, the cells were centrifuged and resuspended in $10 \mathrm{ml}$ of $\mathrm{CDCHO}+8 \mathrm{mM}$ stable $\mathrm{L}$-gln $+15 \mathrm{mg} / \mathrm{L}$ phenol red. A 2-day post-transfection (dpt) selection was started by centrifugation of the cells and resuspension in $4 \mathrm{ml}$ of $\mathrm{CDCHO}+8 \mathrm{mM}$ stable $\mathrm{L}$-gln $+15 \mathrm{mg} / \mathrm{L}$ phenol red $+0.5 \mathrm{mg} / \mathrm{ml} \mathrm{G} 418$ and seeded at 2,500 cells/well in $50 \mu \mathrm{l}$ in a 384 deep-well plate. The plate was fed with $50 \mu \mathrm{l}$ of selection medium $10 \mathrm{dpt}$, and growing wells were expanded to 96 -well plates and finally to $50 \mathrm{ml}$ of shake tubes starting at $16 \mathrm{dpt}$. High-producing subclones were then generated by the second round of single-cell limiting dilution subcloning in 384-well plates to select homogenous monoclonal subclones.

\section{Immobilized Metal Affinity Chromatography Purification of Chimeric Spike Soluble from Initial Cell Pools}

The initial cell pool of pCAGGS-CSs/pCIneo co-transfected CHO-K1 cells was cultivated in 200-ml shake tubes (ST200) at $50-\mathrm{ml}$ working volume in ActiPro supplemented with Cell Boost 1 and 3 (Cytiva) and $8 \mathrm{mML}$-glutamine with a daily medium exchange to increase the maximum cell density, called semicontinuous perfusion process. Tangential flow filtration with a MWCO of $100 \mathrm{kDa}$ was used to concentrate the supernatant and exchange the buffer to $20 \mathrm{mM}$ sodium phosphate $+0.5 \mathrm{M}$ $\mathrm{NaCl}+40 \mathrm{mM}$ imidazole. A HisTrap Fast Flow (FF) column (Cytiva) was used for IMAC purification and CSs was eluted by $20 \mathrm{mM}$ sodium phosphate $+0.5 \mathrm{M} \mathrm{NaCl}+500 \mathrm{mM}$ imidazole. Finally, a PD10 column was used for buffer exchange to PBS, and a $15-\mathrm{kDa}$ Amicon column to concentrate the sample. The protein solution was quantified by total A280 absorbance and frozen to $-80^{\circ} \mathrm{C}$.

\section{Bioprocessing}

The parental stable CSs clone 131A4 and the final subclone CSs C11 (short "C11") were cultivated in different bioprocesses and different media. C11 was cultivated in lab-scale fed-batch bioreactors or subjected to an optimized semi-continuous perfusion protocol.

For semi-continuous perfusion cultivation, $50 \mathrm{ml}$ of cell suspension was seeded at $10 \times 10^{6}$ viable cells $/ \mathrm{ml}$ in a ST200 in $\mathrm{CDCHO}+8 \mathrm{mM} \mathrm{L}$-gln and incubated at $220 \mathrm{rpm}, 50 \mathrm{~mm}$ shaking amplitude, $37^{\circ} \mathrm{C}$, humid $7 \% \mathrm{CO}_{2}$ atmosphere in a Kuhner shaker incubator. Exactly every $24 \mathrm{~h}$, cells were centrifuged at $1,300 \mathrm{rpm}$ for $7 \mathrm{~min}$, the supernatant was collected and stored at $4{ }^{\circ} \mathrm{C}$, and the cell pellet was disrupted and resuspended in fresh pre-warmed medium. An exact protocol for semi-continuous perfusion cultivation can be found in Mayrhofer \& Kunert (2020).

For the integrated perfusion experiment of clone 131A4, a ReadyToProcess WAVE25 bioreactor (Cytiva) was used with ActiPro medium supplemented with Cell Boost 1 and 3 (Cytiva) and $8 \mathrm{mM}$ L-glutamine. An Äkta Pure system equipped with HisTrap Excel was directly integrated with the perfusion harvest line. Fed-batch cultivation was performed in a 500-ml DASGIP system and CDM4HEK293 basal medium fed with Cell Boost 7a and 7b (Cytiva).

\section{Immobilized Metal Affinity Chromatography Purification Strategy}

The supernatant was concentrated and buffer exchanged to running buffer containing $20 \mathrm{mM}$ phosphate buffer, $150 \mathrm{mM} \mathrm{NaCl}, 20 \mathrm{mM}$ imidazole, pH 7.4 by TFF using a $100-\mathrm{kDa}$ membrane. Stepwise elution was initiated by $20 \%, 40 \%, 70 \%$, and $100 \%$ of elution buffer containing $20 \mathrm{mM}$ phosphate buffer, $150 \mathrm{mM} \mathrm{NaCl}, 500 \mathrm{mM}$ imidazole, $\mathrm{pH}$ 7.4. Pooled elution fractions were loaded onto Amicon Ultra-15 centrifugal filter devices with a $100-\mathrm{kDa}$ cutoff, and buffer was exchanged to $20 \mathrm{mM}$ Tris- $\mathrm{HCl}, 150 \mathrm{mM} \mathrm{NaCl}, \mathrm{pH}$ 8.0. Protein content was quantified by total A280 absorbance or quantitative CSs-specific ACE2/anti-His sandwich ELISA. Samples were $0.2 \mu \mathrm{m}$ filtered and snap frozen to $-80^{\circ} \mathrm{C}$.

\section{Quantification of Chimeric Spike Soluble Samples, Determination of Affinity and Serological Evaluation}

A quantitative ACE2/anti-His sandwich ELISA was developed for the quantification of CSs samples. The 96-well MaxiSorp plates (Thermo Fisher) were coated with $5 \mu \mathrm{g} / \mathrm{ml}$ of ACE2 (R\&D systems) in PBS overnight at $4^{\circ} \mathrm{C}$ or $2 \mathrm{~h}$ at room temperature. Unknown samples or $1 \mu \mathrm{g} / \mathrm{ml}$ of purified CSs standard were serially diluted in PBS with $0.1 \%$ Tween (TPBS) and 1\% BSA. Coated plates were washed with TPBS, and the applied samples were incubated for $1 \mathrm{~h}$ at room temperature. Biotinylated anti-His (Thermo Scientific) detection antibody was diluted at 1:1,000 in TPBS $+1 \%$ BSA and incubated on the plate for $1 \mathrm{~h}$ at room temperature. Streptavidin-HRP conjugate (Roche) was diluted at 1:5,000 in TPBS + 1\% BSA and incubated on the plate for $30 \mathrm{~min}$ at room temperature. The color reaction was developed using TMB substrate and stopped with concentrated $\mathrm{H}_{2} \mathrm{SO}_{4}$ followed by OD 450-nm measurement at 620-nm reference. The EC50 value of CSs binding to ACE2 was determined by fitting a non-linear four-parametric sigmoidal log model on the absorbance values at different CSs molar concentrations. To evaluate the binding affinity of the anti-SARS monoclonal antibody CR3022, purified CSs protein $(5 \mu \mathrm{g} / \mathrm{ml})$ was coated, and serially diluted biotinylated CR3022 was prepared starting at $2 \mu \mathrm{g} / \mathrm{ml}(13 \mathrm{nM})$ in TPBS $+1 \%$ BSA. After incubation for $1 \mathrm{~h}$ at room temperature, the detection was performed with streptavidin-HRP conjugate (1: 5,000) and TMP substrate.

A similar ELISA setup was used to confirm the CSs protein quality with vaccinated donor samples. CS-coated plates were blocked for $1 \mathrm{~h}$ at room temperature with TPBS containing 3\% of non-fat skim milk powder (MP). Samples were diluted in TPBS with 3\% MP and incubated for $2 \mathrm{~h}$ at room temperature. Antihuman gamma-HRP detection antibody (Invitrogen) was diluted at 1:5,000 and incubated for $1 \mathrm{~h}$ at room temperature. A color reaction was developed using the TMB substrate.

EC50 values were determined by fitting a non-linear fourparametric sigmoidal log model on the absorbance values at different CSs molar concentrations. 


\section{Isolation and Biotinylation of Polyclonal Anti-SARS-CoV-2 Hyperimmune Ig}

SARS-CoV-2 convalescent plasma (Takeda) was thawed and cryoprecipitated at $4^{\circ} \mathrm{C}$ for $2 \mathrm{~h}$ followed by centrifugation at $5,000 \times g$ for $15 \mathrm{~min}$. Supernatant, $1 \mathrm{ml}$, was diluted with $2 \mathrm{ml}$ of PBS, and $2.45 \mathrm{ml}$ of saturated ammonium sulfate was added under continuous stirring, and the mixture was incubated at $4{ }^{\circ} \mathrm{C}$ for $5 \mathrm{~h}$. After centrifugation at $1,000 \times g$ for $15 \mathrm{~min}$, the precipitate was washed with $5 \mathrm{ml}$ of $45 \%$ saturated ammonium sulfate solution and centrifuged at $1,000 \times g$ for $15 \mathrm{~min}$. The pellet was resuspended in $1 \mathrm{ml}$ PBS and centrifuged again at $1,000 \times g$ for $2 \mathrm{~min}$. The supernatant was dialyzed against PBS overnight at $4^{\circ} \mathrm{C}$ and centrifuged again at $10,000 \times g$ for $5 \mathrm{~min}$. Following 0.22 $\mu \mathrm{m}$ filtration and storage at $4^{\circ} \mathrm{C}, 1 \mathrm{ml}$ of cryo- and ammonium sulfate precipitated hyperimmune serum was diluted with $9 \mathrm{ml}$ of phosphate buffer and loaded onto a protein A affinity column. Polyclonal hyperimmune IgGs were eluted with $50 \mathrm{mM}$ sodium acetate $\mathrm{pH} 3.5$ and neutralized with Tris- $\mathrm{HCl} \mathrm{pH}$ 8.0. Hyperimmune IgG, $1.54 \mathrm{mg}$, was biotinylated using the EZLink NHS-PEG4-Biotin kit (ThermoFisher).

\section{SDS-PAGE and Western Blotting}

Bis-Tris NuPAGE polyacrylamide gels, $4 \%-12 \%$, were run in MOPS SDS running buffer. Samples were incubated with NuPAGE LDS sample buffer for $10 \mathrm{~min}$ at $70^{\circ} \mathrm{C}$ for nonreducing conditions or additionally mixed with NuPAGE reducing agent and incubated for $5 \mathrm{~min}$ at $98^{\circ} \mathrm{C}$ for reducing conditions. The gels were run at $200 \mathrm{~V}$ for approximately $1 \mathrm{~h}$ at room temperature. A PVDF membrane was activated for $1 \mathrm{~min}$ with methanol $(\mathrm{MeOH})$ and rinsed with NuPAGE transfer buffer in $20 \% \mathrm{MeOH}$ for Western blotting. Proteins were blotted from the SDS-Gel onto the PVDF membrane using a PerfectBlue "Semi-Dry" Electro Blotter (peqlab) at $10 \mathrm{~V}, 3 \mathrm{~mA} / \mathrm{cm}^{2}$ for $1 \mathrm{~h}$. The blotted membrane was blocked with 5\% BSA in TPBS for $1 \mathrm{~h}$ or overnight and washed with TPBS. Detection was performed for $1 \mathrm{~h}$ with primary detection antibody in TPBS with $0.5 \%$ BSA. Secondary detection was performed with streptavidin-HRP conjugate in TPBS with $0.5 \%$ BSA for $30 \mathrm{~min}$. Chemiluminescence was induced with the SuperSignal West Pico Plus substrate (Thermo Fisher).

\section{RESULTS AND DISCUSSION}

\section{SARS-CoV-2 Chimeric Spike Soluble Protein from a G418 Selected Early Transfection Pool}

Preliminary material of a new protein of interest is needed to rapidly develop analytical methods supporting the selection of high-producing subclones during clone development. The originally received plasmid (pCAGGS-CSs) (Amanat et al., 2020) was co-transfected with a vector (pCIneo) containing a suitable G418 selection marker in a quick and straightforward effort. Transfection pools were generated by lipofection, G418 pool selection and after recovery of the viability above $95 \%$, expansion to higher cell concentration using shake tube bioreactors. A semi-continuous perfusion culture starting already 25 days post-transfection was used to generate enough protein to develop analytical methods. Using a daily medium exchange protocol, high cell densities of $50 \times 10^{6}$ viable cells $/ \mathrm{ml}$ were achieved and passaged once to maintain high viability (Figure 1A). The culture supernatant for optimization of the IMAC purification step was collected from harvests of the semicontinuous perfusion culture of the initial transfection pool.

The purified CSs preparation (Figures 1B, C) was suitable to support essential analytical methods for further clone development (Table 1). The analytical workflow aims to screen, identify, and select high-producing clones. The rapid production of a new recombinant protein such as the SARS CoV-2 spike protein faces several challenges, particularly the availability of suitable reagents (Esposito et al., 2020). One strategy is to use generic analytic methods, e.g., total protein visualization by SDS gel electrophoresis, or ELISA-based methods that detect commonly used protein tags (e.g., 6xHis). However, these methods only provide limited information about the quality of the expressed protein. Thus, several strategies to detect the functional spike protein were pursued in parallel and are summarized in Table 1. Already quite early in the pandemic, the monoclonal antibody CR3022 binding to the receptor binding domain (RBD) of SARS$\mathrm{CoV}-2$ spike protein was available. This $\mathrm{mAb}$ was initially discovered to be specific for SARS CoV (van den Brink et al., 2005) and is commercially available. To be independent of the global market, we also harvested culture supernatants from the early transfection/ selection pool and of subclones of recombinant CR3022 CHO-K1 cells and cultivated them in fed-batch bioreactors to yield low but sufficient $10 \mathrm{mg} / \mathrm{L}$ of $\mathrm{mAb}$ titer at harvest. The ACE2 receptor was commercially available and used for analytical purposes. Using these and other commonly available reagents, various ELISA setups were tested and optimized and the ACE2/anti-His sandwich ELISA gave the best reproducible outcomes.

\section{Recombinant CHO-K1 Cells Stably Expressing SARS-CoV-2 Chimeric Spike Soluble Spike Protein}

The pL-CSs construct was used for the generation of recombinant $\mathrm{CHO}-\mathrm{K} 1$ cell lines stably expressing SARS-CoV-2 spike protein. Purified CSs protein from the initial pool experiment (Figure 1) was used as reference material to select the best producing CSs subclones, as shown in the following ELISA experiments (Figure 2). Parental clone 131A4 reproducibly gave the highest titers and good growth behavior and was selected as the leading parental cell clone.

Finally, the parental clone 131A4 was selected for limited dilution subcloning. Three subclones were selected by ELISA quantification of cell culture supernatants and further expanded into shake cultures to characterize growth behavior and productivity (Figure 3). Subclone C11 showed high growth rates of 0.8 days $^{-1}$ comparable with the parental clone and highest titers of $6 \mathrm{mg} / \mathrm{L}$ after 3 to 4 days of routine cultivation (Figures 3A, B). All clones showed the correct mass of the monomeric spike protein in Western blotting under reducing 
A<smiles>C[18O]</smiles>

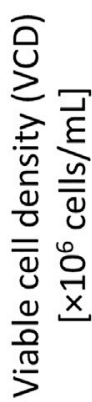

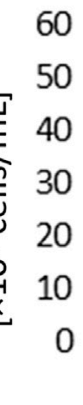

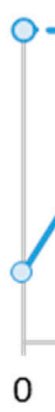

믄 Viability

$V C D$<smiles>OOOOOOOOO</smiles>

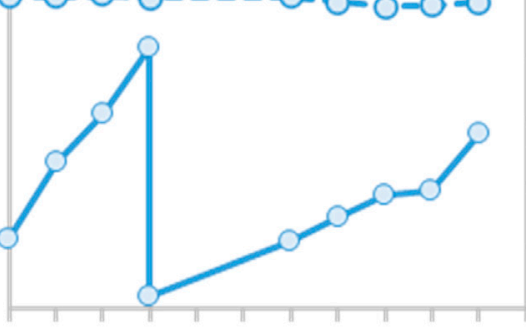

$\begin{array}{llllllllllll}0 & 1 & 2 & 3 & 4 & 5 & 6 & 7 & 8 & 9 & 10 & 11\end{array}$
100

80

60

40

20

Process time [days]

B

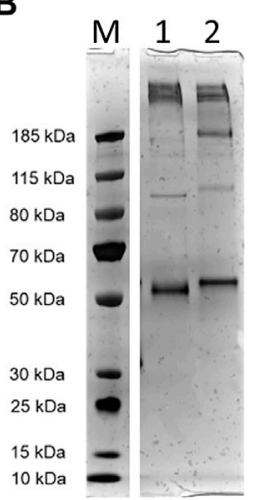

C

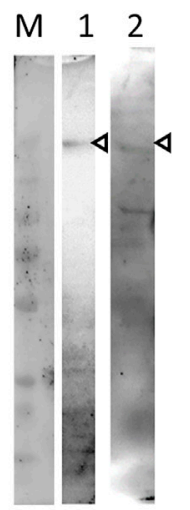

FIGURE 1 | After co-transfection of vectors pCAGGS-chimeric spike soluble (CSs) and pClneo, and selection of transfection pools for 25 days, a 50-ml semicontinuous perfusion cultivation was started (A). Samples from immobilized metal affinity chromatography (IMAC) (HisTrap) purification were analyzed by $4 \%-12 \%$ BisTris SDS-PAGE (silver stain) (B) under non-reducing (lane 1, 500 ng of total protein) and reducing conditions (lane 2, 500 ng of total protein) and Western blotting (C)

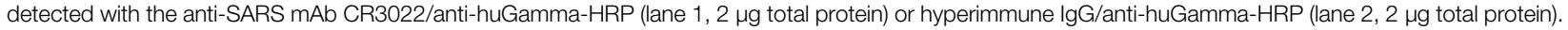

TABLE 1 | ELISA and Western blotting repertoire for analytical screening of chimeric spike soluble (CSs) subclones and to verify the quality and functionality of the expressed CSs protein.

\begin{tabular}{|c|c|c|c|}
\hline \multirow{7}{*}{$\begin{array}{l}\text { Sandwich } \\
\text { ELISA }\end{array}$} & Coating protein & Detection mAb & Comment \\
\hline & ACE2 & $\begin{array}{l}\text { Anti-His-HRP or anti- } \\
\text { His-btn }\end{array}$ & High signal used for CSs sample quantification and EC50 quantification (Figure $\mathbf{2}$ and $\mathbf{8 C}$ ) \\
\hline & ACE2 & CR3022-btn & $\begin{array}{l}\text { Limited CSs detection based on up/down conformation of the RBD-domain (Henderson et al., 2020; } \\
\text { Yuan et al., 2020) }\end{array}$ \\
\hline & ACE2 & Hyperimmune lgG-btn & Low signal (data not shown) \\
\hline & CR3022 & $\begin{array}{l}\text { Anti-His-HRP or anti- } \\
\text { HIS-btn }\end{array}$ & $\begin{array}{l}\text { Limited CSs detection based on up/down conformation of the RBD-domain (Henderson et al., 2020; } \\
\text { Yuan et al., 2020) }\end{array}$ \\
\hline & $\begin{array}{l}\text { Hyperimmune } \\
\text { lgGs }\end{array}$ & $\begin{array}{l}\text { Anti-His-HRP or anti- } \\
\text { HIS-btn }\end{array}$ & low signal (data not shown) \\
\hline & Purified CSs & Anti-human-gamma-HRP & Serological ELISA (Figure 8E) \\
\hline \multirow[t]{4}{*}{ Direct ELISA } & Coating protein & Detection protein & - \\
\hline & Purified CSs & CR3022-btn & Strong signal used for EC50 determination (Figure 8D) \\
\hline & Purified CSs & Hyperimmune IgG-btn & Serological evaluation of CSs (data not shown) \\
\hline & ACE2 & Purified CSs -btn & Not tested. It can be used for binding interaction studies (EC50) \\
\hline \multirow{4}{*}{$\begin{array}{l}\text { Western } \\
\text { blotting }\end{array}$} & - & Detection mAb & - \\
\hline & & $\begin{array}{l}\text { Anti-His-HRP or anti- } \\
\text { His-btn }\end{array}$ & Strong signal (Figure $\mathbf{3 C}$ ) \\
\hline & & CR3022-btn & Strong signal (Figure 8A) \\
\hline & & Hyperimmune lgG-btn & Strong signal (Figure 7C) \\
\hline
\end{tabular}

and denaturing conditions detected with anti-His or hyperimmune IgGs (Figure 3C).

\section{Scale-up of Spike Protein Expression by Perfusion Cultivation and Hypothermic Fed-Batch Cultivation}

The parental CSs clone 131A4 was used in an integrated $500 \mathrm{ml}$ perfusion bioreactor directly connected to the Äkta Pure system equipped with a HisTrap Excel column (Figure 4) to generate large harvest volumes compensating for the relatively low product titer. The perfusion rate of 0.2 vessel volumes per day (vvd) was kept constant from days 3 to 8 followed by a stepwise increase to $2 \mathrm{vvd}$ on day 11 to prevent nutrient limitation. In the steady-state of the perfusion, the viable cell density (VCD) reached $80 \times 10^{6}$ viable cells/ml, maintained by a continuous cell bleed starting on day 8 (Figure 4A). This adjustment translates into optimized cellspecific perfusion rates between 10 and $40 \mathrm{pl}$ medium per cell per day $(\mathrm{pL} / \mathrm{c} / \mathrm{d})$ for minimized medium consumption and increased product titer. Integrated direct purification was initiated on day 5. 

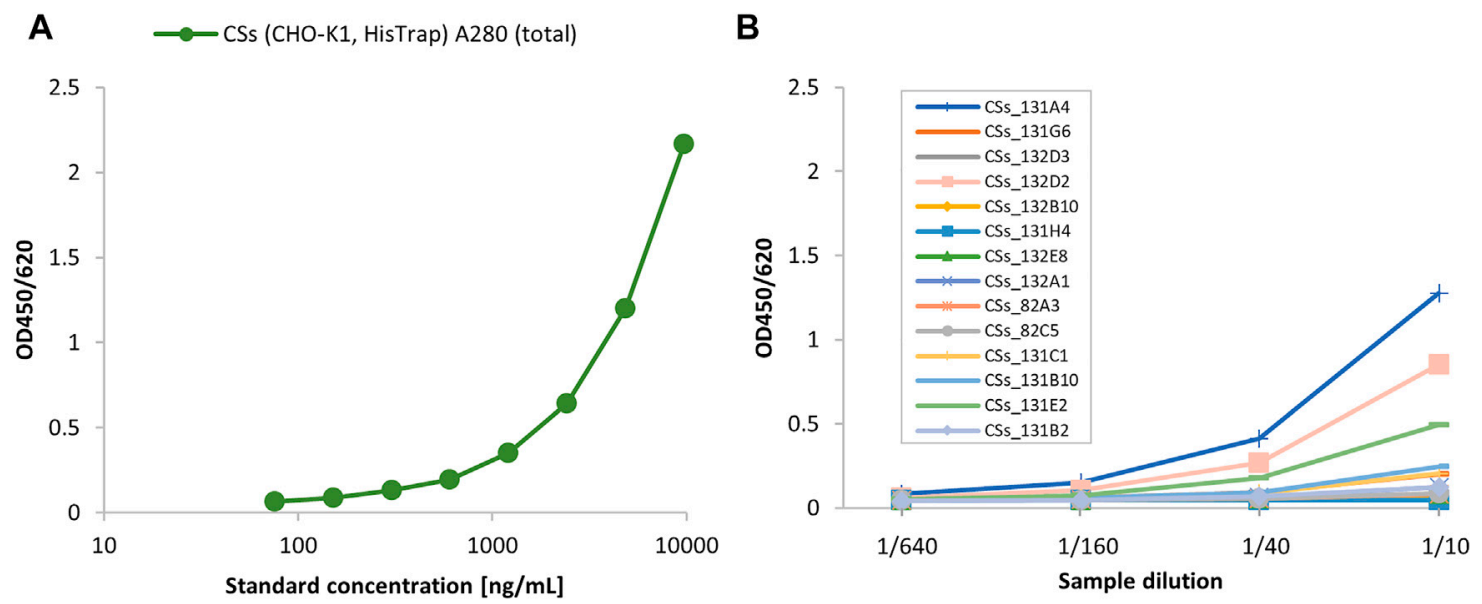

FIGURE 2 | Screening of various parental CSs subclones using the angiotensin-converting enzyme 2 (ACE2)/anti-His sandwich ELISA. The initially purified CSs material from the cell pool cultivation was used as ELISA standard (10 $\mu \mathrm{g} / \mathrm{ml}$ total protein by A280 absorbance) (A) to screen parental CSs subclones (B).
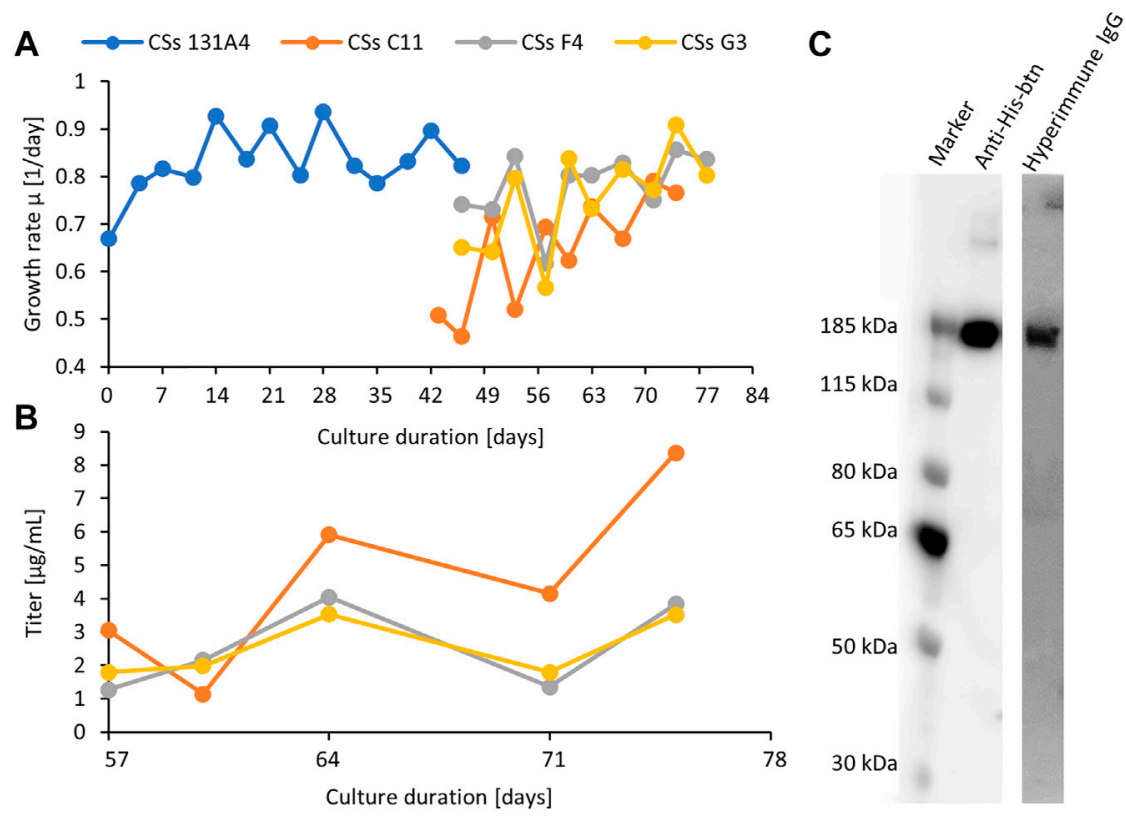

FIGURE 3 | Expansion and monitoring of growth (A) and productivity (B) of the first parental clone CSs $131 \mathrm{~A} 4$ and three final CSs daughter clones in shake tube cultures. The clone CSs C11 was selected as the final high-producing subclone. Anti-His and hyperimmune lgG Western blotting (C) of C11 supernatant (12 $\mu$ l, 100 ng) indicate the presence of the recombinant CSs protein in a structurally functional form to bind to specific antibodies. Lane 1, anti-His-btn; lane 2, hyperimmune IgG-btn.

The continuous perfusion harvest was mixed continuously with $50 \%(\mathrm{v} / \mathrm{v})$ of phosphate buffer and loaded onto a HisTrap Excel column. This column minimizes metal stripping off the column caused by extended exposure to the cell culture medium. The first IMAC elution fraction was collected the day after loading and dialyzed against $20 \mathrm{mM}$ Tris- $\mathrm{HCl}, 150 \mathrm{mM} \mathrm{NaCl}, \mathrm{pH}$ 8.0. Highmolecular weight species were visible in silver-stained SDS-PAGE (Figure 4B) that were enriched in the dialyzed product (lane 4) compared with the IMAC elution fraction (lane 3). These aggregates were partly resolved under reducing conditions (lane 9). Inefficient binding of the CSs protein led to significant amounts of CSs protein in the flow-through fraction (FT, lane 1 and 6) and wash fraction (WS2, lane 2 and 7). Thus, although the perfusion process in the bioreactor was successful and high performing concerning the cell culture parameters, further optimization would be required for the integrated downstream purification process for optimized yield and purity in the eluate fraction.

In another experiment, the final CSs clone C11 was cultivated in lab-scale fed-batch bioreactors. Various fed-batch strategies were tested to boost final spike protein titers in the culture supernatant. Valproic acid (VPA) is a small molecule 


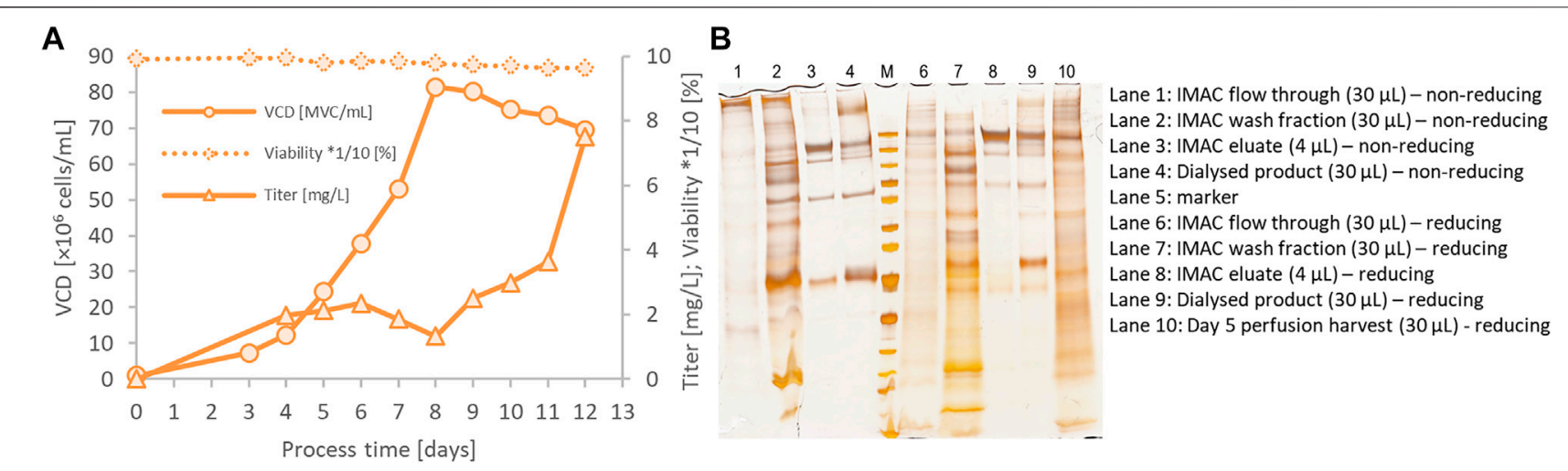

FIGURE 4 | $500 \mathrm{ml}$ bioreactor perfusion run for integrated bioprocessing of the CSs spike protein using a preliminary low-producing subclone (CHO-K1 CSs 131A4) (A). The bioreactor harvest was coupled directly to an Äkta Pure system equipped with a HisTrap Excel column. On day 8 , cell bleeding was started to keep viable cell density (VCD) below $80 \times 10^{6}$ viable cells/ml. IMAC fractions, dialyzed end product, and perfusion harvest on day 5 were analyzed by silver-stained SDS-PAGE (B).

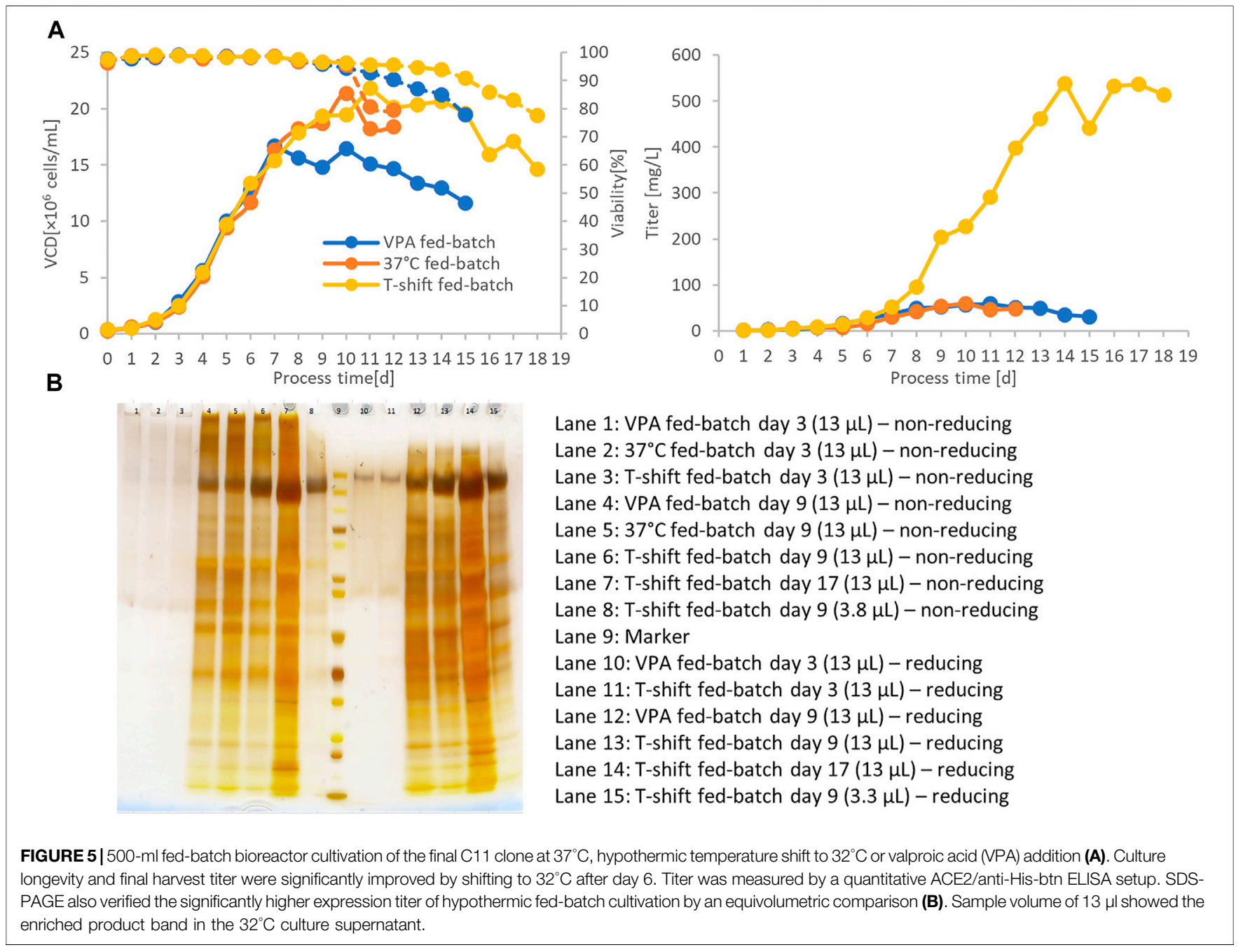

compound that improves protein expression in mammalian cells, acting as an inhibitor of histone deacetylases (iHDAC). Furthermore, hypothermic cultivation temperatures limit cellular growth but increase cell-specific recombinant protein expression. In transient spike protein expression, a beneficial effect of lowered culture temperatures was demonstrated that led 

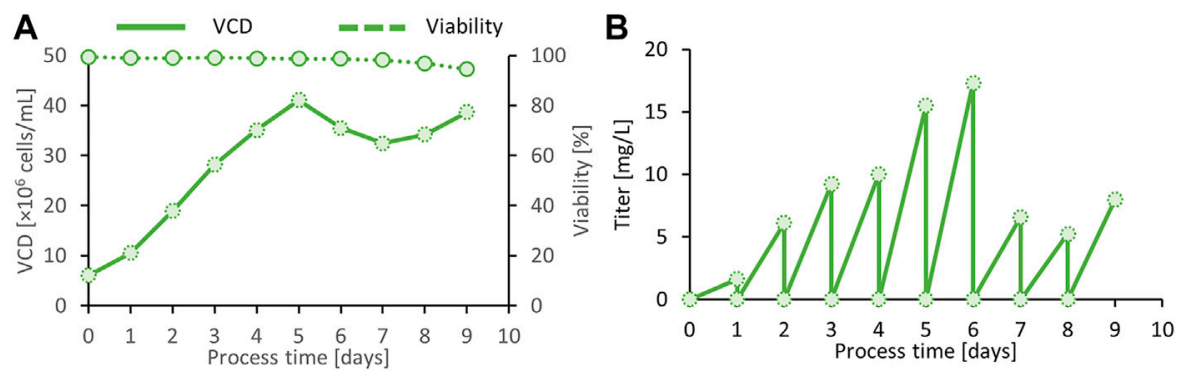

FIGURE 6 | Viable cell density (VCD) and viability of the final clone C11 producing the SARS CoV-2 spike protein in semi-continuous perfusion mode (A). Daily harvest titer was measured by a quantitative ACE-2/anti-His sandwich ELISA (B)

to titer enhancements of more than 10 -fold in previous studies (Esposito et al., 2020). In another study, hypothermic conditions and VPA addition increased product titers by a factor of five in stable CHO pools (Johari et al., 2021). Using the selected production clone $\mathrm{C} 11$ in bioreactor fed-batch cultivation, we observed that viability dropped to $80 \%$ on day 11 at standard $37^{\circ} \mathrm{C}$ cultivation temperature (Figure 5A). Culture longevity was induced by a hypothermic temperature shift to $32^{\circ} \mathrm{C}$ after day 6 or a single shot of valproic acid on day 6. A maximum $\mathrm{VCD}$ of $20 \times 10^{6}$ viable cells $/ \mathrm{ml}$ was reached for both the standard $37^{\circ} \mathrm{C}$ and hypothermic $32^{\circ} \mathrm{C}$ cultures, but only $15 \times 10^{6}$ viable cells $/ \mathrm{ml}$ for the culture supplemented with VPA. Hypothermic conditions prolonged process duration up to 18 days at viabilities above $80 \%$. Despite the induction of higher cellspecific productivities, VPA addition was not suitable to obtain higher CSs titers because of reduced VCD.

Interestingly, hypothermic treatment has induced exceptionally high product titers of up to $500 \mathrm{mg} / \mathrm{L}$. Despite similar peak VCD, the temperature shift has induced a harvest titer 10-fold higher than the default fed-batch process of $37^{\circ} \mathrm{C}$. In order to eliminate the possibility of artifacts in the ELISA quantification due to misfolded CSs from the hypothermic condition, equal supernatant volumes from the different fed-batch conditions were applied on an SDS-PAGE for selected culture days (days 3 and 9). An enriched product band confirmed higher product titers under the hypothermic fed-batch condition (Figure 5B, lane 7 and 14).

Alternatively, we developed a small-scale semi-continuous perfusion culture that keeps cells in a healthy state for prolonged periods at exceptionally high cell densities of $40 \times 10^{6}$ viable cells $/ \mathrm{ml}$ in uncontrolled $200-\mathrm{ml}$ shake tubes. This procedure follows a daily medium exchange of one reactor volume per day and provides daily supernatant harvests of up to $15 \mathrm{mg} / \mathrm{L}$ spike protein (Figure 6). Compared with the fed-batch process, cells at higher VCD are kept at higher viabilities, and consequently, the best product quality can be expected.

\section{Optimized Immobilized Metal Affinity Chromatography for Highly Pure and Functional Trimeric Spike Protein Preparation}

Immobilized metal affinity chromatography (IMAC) was chosen as the preferred purification method of the CSs protein by using a chelating HisTrap column loaded with Ni-ions and a stepwise increased imidazole gradient. In the first experiment, elution buffer was increased in 5\% increments and fractions analyzed by ELISA. In fractions with low imidazole concentration, the bound spike protein coelutes with host-cell proteins, whereas, at higher imidazole concentrations, the spike protein can be isolated in a pure form. Consequently, a stepwise elution profile at $20 \%$, $40 \%, 70 \%$, and $100 \%$ of $500 \mathrm{mM}$ imidazole concentration was defined in $20 \mathrm{mM}$ phosphate buffer with $150 \mathrm{mM} \mathrm{NaCl}, \mathrm{pH} 7.4$ and was used to purify the culture supernatant from the semiperfusion process (Figure 7A). Different HisTrap elution fractions were analyzed by non-reducing SDS-PAGE/silver stain (Figure 7B), Western blotting with hyperimmune IgG (Figure 7C), and SEC-HPLC (Figure 7D). This confirmed that CSs protein can be isolated with high purity from the 40\% gradient step (fraction B9-C6) (Figure 7A).

IMAC purification shows several disadvantages concerning low binding affinity (Riguero et al., 2020), coelution of host-cell proteins, ion stripping, and incompatibility of cell culture media components (Farnós et al., 2020; Johari et al., 2021). Thus, many laboratories later switched to alternative affinity chromatography resin (e.g., Strep-Tactin). Although we developed a suitable purification protocol for highly pure spike protein, a significant fraction of the expressed protein was lost in the first wash step. Furthermore, significant amounts of CSs protein were detected in the flow-through. This was also observed by Stuible et al. (2021) for a $\mathrm{Ni}$-Sepharose excel resin and attributed the reduced binding capacity to the size and/or shape of the spike construct, which may prevent diffusion into the pores. Further optimization of the IMAC procedure would be required to improve the final yield by optimizing the step gradient, choosing a gradient elution profile, or alternative purification methods (Cibelli et al., 2021).

The IMAC purified CSs protein was characterized in more detail by SDS-PAGE, Western blotting, ELISA, and N-glycan analysis (Figure 8 and Figure 9). A single defined band with the correct size of the CSs monomeric chain was observed in nonreducing SDS-PAGE and Western blotting using biotinylated hyperimmune IgG, CR3022, or anti-His mAbs (Figure 8A). The SEC profile showed the characteristic double peak with the correct molar mass of a fully glycosylated and trimeric CSs protein (Figure 8B). EC50 against ACE2 or CR3022 was determined at 0.1 and $0.4 \mathrm{nM}$, respectively (Figures 8C, D) 


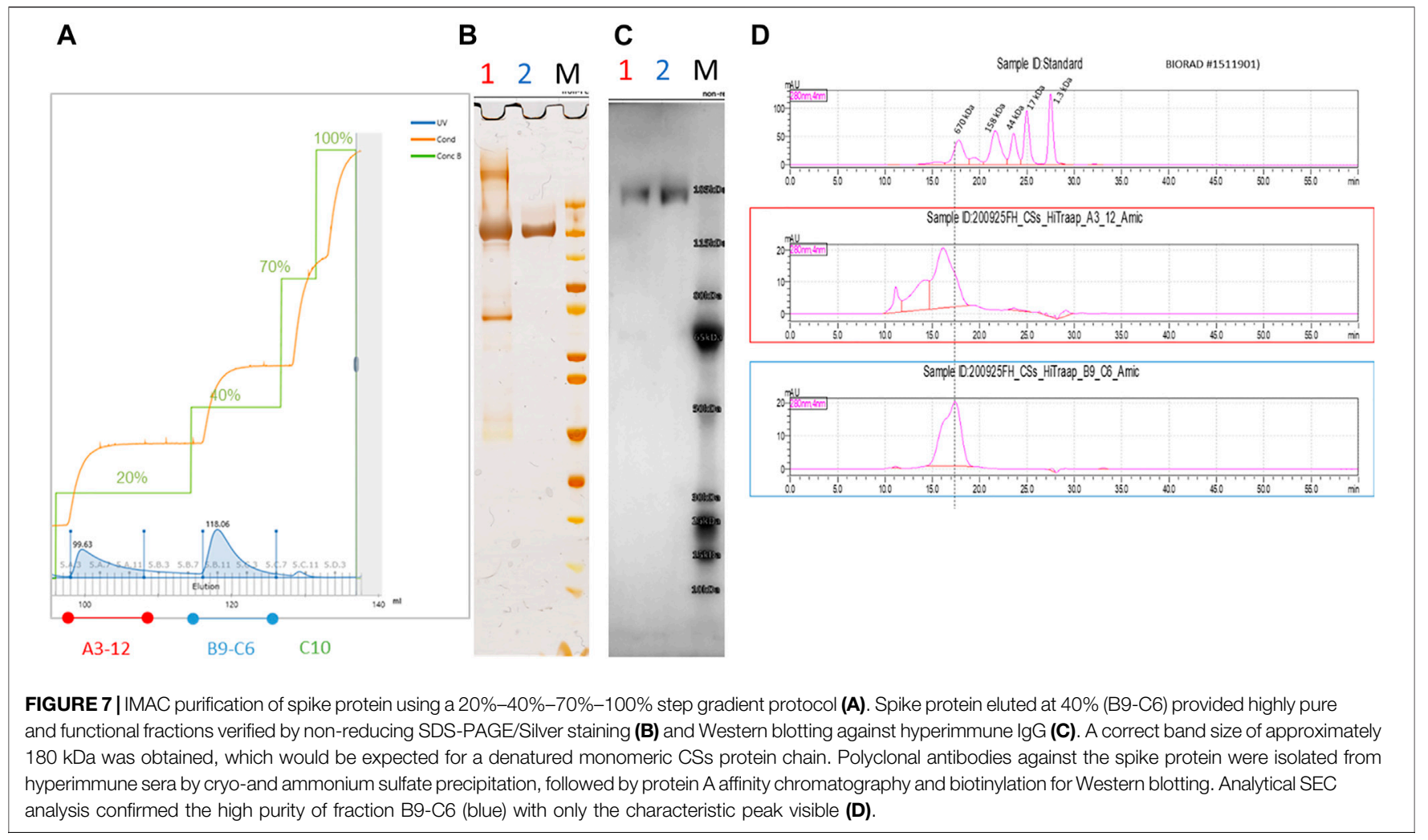

A

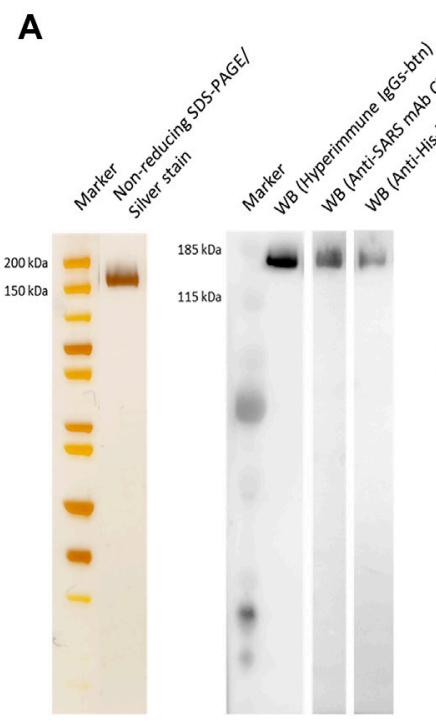

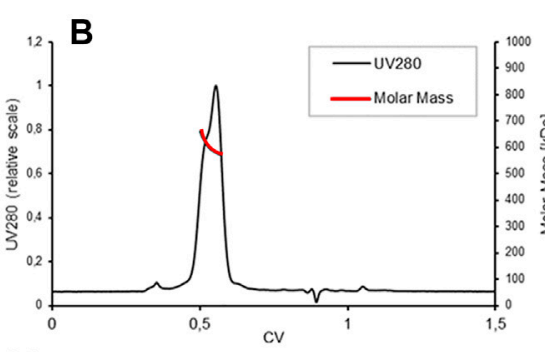

D

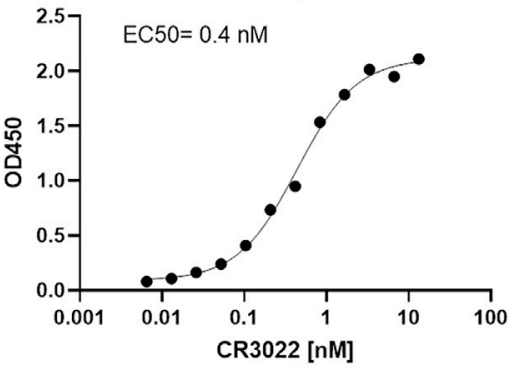

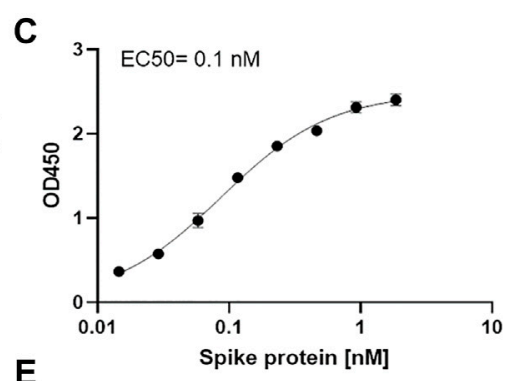

E

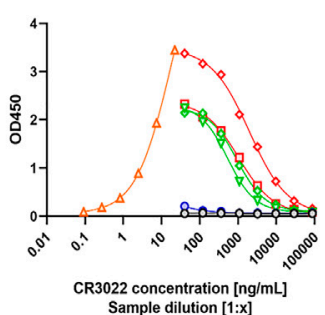

-o- Blank

-. COVID neg (not vaccinated)

$\rightarrow-1$ st AstraZeneca (person 1)

$\diamond$ 2nd AstraZeneca (person 2)

마- COVID pos (patient 1)

$\rightarrow$ COVID pos (patient 2)

$\triangle \mathrm{CR} 3022$

FIGURE 8 | Non-reducing SDS-PAGE of the pure CSs spike protein preparation gives a single intense band (2 $\mu \mathrm{g}$ loaded) after silver stain and various Western blotting setups using hyperimmune IgG, anti-SARS mAb CR3022, or anti-His antibodies (A). Analytical SEC/MALS-HPLC by a Superose 6 increase 10/300 GL column (Cytiva) indicates the high purity of the IMAC preparation with the characteristic double peak of the spike protein (B). The molar mass of the trimeric spike is about $610 \mathrm{kDa}$ (MALS signal) and elutes at $0.55 \mathrm{CV}$. The purity of the trimer fraction is $>90 \%$. Determination of affinity (EC50) of spike protein to ACE2 (C): ACE2 was coated on ELISA plates, and the bound CSs spike protein was detected by anti-His-btn/SA-HRP conjugates. The purified spike protein preparation showed high affinity to the anti-SARS mAb CR3022 (D): Coating: $5 \mathrm{\mu g} / \mathrm{ml}$ spike protein and detection with CR3022-btn/SA-HRP conjugates. A sigmoidal non-linear four-parametric log model was used for the calculation of the EC50. The purified spike protein was applied to a serological ELISA set up to detect spike-specific antibodies in COVID-positive individuals or individuals vaccinated with one or two doses of the AstraZeneca vaccine (E): coating $5 \mu \mathrm{g} / \mathrm{ml}$ of spike protein and detection with anti-huGamma-HRP. 


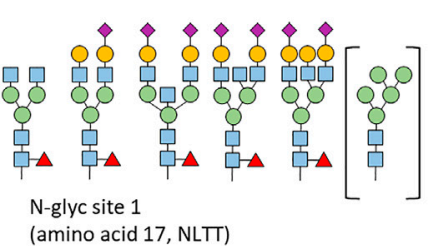

(amino acid 17, NLTT)

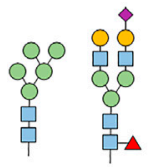

$\mathrm{N}$-glyc site 2

(amino acid 61, NVTW)

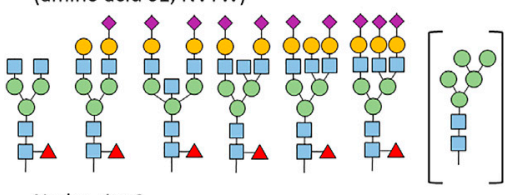

N-glyc site 3

(amino acid 74, NGTK)

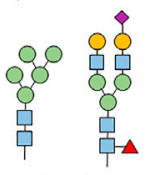

$\mathrm{N}$-glyc site 4

(amino acid 122, NATN )

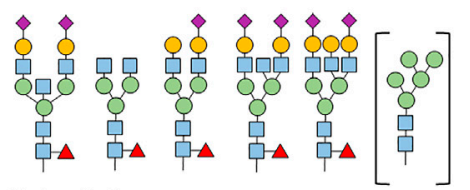

$\mathrm{N}$-glyc site 5

(amino acid 149, NKSW)

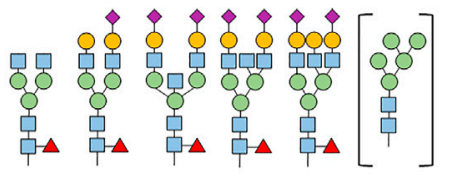

$\mathrm{N}$-glyc site 6

(amino acid 165, NCTF)

900

go

$\mathrm{N}$-glyc site 7

(amino acid 234, NITR)

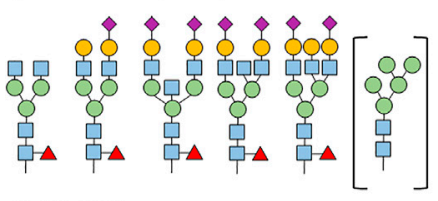

$\mathrm{N}$-glyc site 8

(amino acid 282, NGTI)

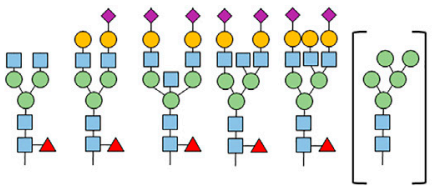

$\mathrm{N}$-glyc site 9

(amino acid 331, NITN)

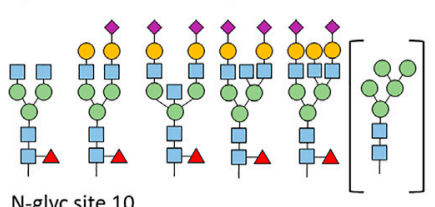

$\mathrm{N}$-glyc site 10

(amino acid 343, NATR)

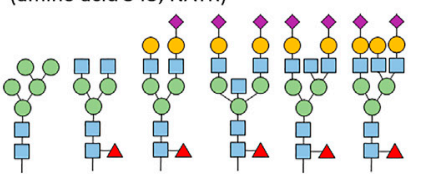

$\mathrm{N}$-glyc site 11

(amino acid 603, NTSN)

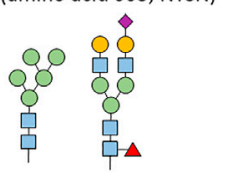

$\mathrm{N}$-glyc site 12

(amino acid 616, NCTE)

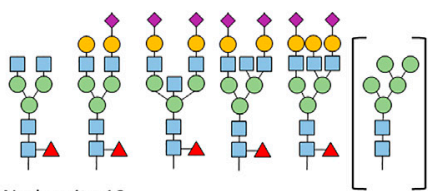

$\mathrm{N}$-glyc site 13

(amino acid 657, NNSY)

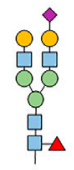

$\mathrm{N}$-glyc site 14

(amino acid 706, NNSI)

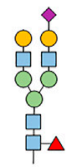

$\mathrm{N}$-glyc site 15

(amino acid 714, NFTI)

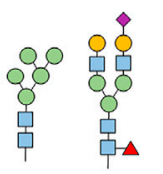

$\mathrm{N}$-glyc site 16

(amino acid 798, NFSQ)

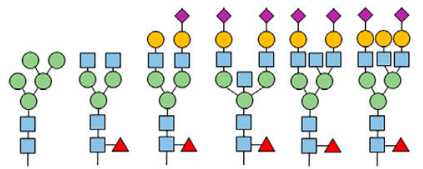

$\mathrm{N}$-glyc site 17

(amino acid 1071, NFTT)

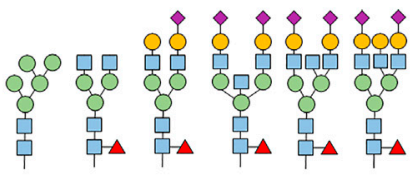

$\mathrm{N}$-glyc site 18

(amino acid 1095, NGTH)

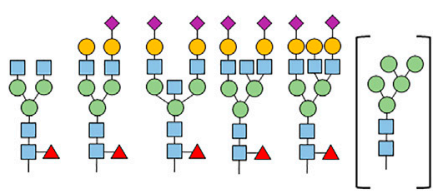

$\mathrm{N}$-glyc site 19

(amino acid 1131, NNTV)

[not detected]

$\mathrm{N}$-glyc site 20

(amino acid 1155, NHTS)

[not detected]

$\mathrm{N}$-glyc site 21

(amino acid 1170, NASV)

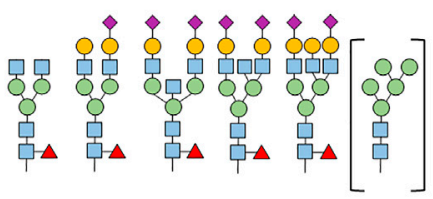

$\mathrm{N}$-glyc site 22

(amino acid 1191, NESL)

FIGURE 9 | Qualitative N-glycosylation analysis of CSs spike protein by LC-ESI-MS/MS.

and agrees with previously published literature (Tian et al., 2020; Walls et al., 2020). The purified CSs spike protein was then successfully applied in serological ELISAs against COVID negative and positive sera or vaccinated individuals. The produced spike protein generated a strong response for binding of anti-SARS mAb CR3022 and anti-SARS-CoV-2 
hyperimmune IgG present in convalescent sera of COVID patients or vaccinees after one or two doses of the AstraZeneca vaccine (Figure 8E).

$\mathrm{N}$-glycosylation was qualitatively analyzed by LC-ESI-MS/MS analysis (Figure 9). The identified glycosylation patterns are in agreement with previously published glycan patterns of the spike protein. Specifically, for sites $2,4,7,11,16$, and 17, a significant fraction of oligomannose type was reported in the literature (Watanabe et al., 2020; Allen et al., 2021; Hoffmann et al., 2021).

\section{CONCLUSION}

Efficient spike protein expression is crucial for biomedical research, subunit vaccine production, and the development of serological tests to screen the success of vaccines and evaluate the immunological status of previous infections. Thus, at the pandemic onset, the goal was to rapidly produce the novel spike protein in large quantities at the highest quality. It is evident that transient transfection has established itself as the preferred method to produce low amounts rapidly but with significant resources and costs at small-scale. Literature on stable cell lines expressing the viral spike protein for large-scale production is scarce due to the complexity and timely process of generating clonally derived, high-producing cell lines. Compared with 19 transient approaches only three publications with stable cell lines were found in the rather extensive literature search (Allen et al., 2021; Cibelli et al., 2021; Johari et al., 2021). We demonstrate how the established technological repertoire in mammalian cell expression can be efficiently adapted to express the trimeric spike protein in large amounts in stable clonally derived $\mathrm{CHO}$ cell lines. The $\mathrm{CHO}-\mathrm{K} 1$ host cell line previously showed beneficial capabilities for growth and productivity compared with other host cell lines (Reinhart et al., 2018) and was used to generate recombinant CSs producing subclones. Furthermore, the $\mathrm{CHO}-\mathrm{K} 1$ host shows beneficial glycosylation capabilities and is safe regarding the risk of contamination and transmission of human pathogens. Low but sufficient amounts of spike protein were initially produced with an early transfection pool by a small-scale semicontinuous or lab-scale bioreactor perfusion process. During the clone development workflow, it is crucial to generate and provide spike protein from low-producing cell pools to develop specific analytical and downstream purification methods. These methods enabled us to establish high-producing, clonally derived cell lines, which were then used to develop a fed-batch process at $20 \times 10^{6}$ cells $/ \mathrm{ml}$.

Interestingly, a hypothermic fed-batch temperature shift to $32^{\circ} \mathrm{C}$ induced a 10 -fold increase in the final harvest titer. As Johari et al. (2021) pointed out, improved purification methods are required to cope with host cell impurities at high cell densities. Thus, we also developed a continuous bioreactor perfusion process at $80 \times 10^{6}$ cells $/ \mathrm{ml}$ or semi-continuous shake tube bioprocesses operated at the highest cell viabilities above $95 \%$ over a prolonged time. While the presented IMAC purification step gradient provided a sufficient amount of highly pure CSs protein from highly productive cell cultures, it was not further optimized to provide the highest yields due to co-elution with host cell proteins and product loss at low imidazole concentrations. Recently, an optimized IMAC method or alternative capture methods were demonstrated for SARS-CoV-2 spike proteins (Cibelli et al., 2021; Johari et al., 2021). The development of robust protocols finally enabled assessing the quality of the expressed spike protein by various setups for Western blotting and ELISA. The purified spike protein from stable high-producing $\mathrm{CHO}$ clones showed the correct band size in SDS-PAGE and Western blotting using anti-His, the anti-SARS mAb CR3022, and polyclonal antibodies isolated from convalescent plasma. Analytical SEC-MALS showed high purity of the spike protein preparation from the optimized IMAC protocol. However, the purification protocol was optimized for purity and quality that came with costs for product yield. The purified spike protein showed high affinity to the ACE2 receptor and the anti-SARS mAb CR3022 in the established ELISA. Finally, the purified spike protein was successfully applied in a serological ELISA setup to screen COVID-positive sera and two of vaccinated individuals.

In summary, this study demonstrates the optimal combination of $\mathrm{CHO}-\mathrm{K} 1$ host cell line, expression vector, and fed-batch or continuous bioprocesses to produce the complex spike protein in large amounts at the highest quality and is already used successfully in ongoing serological studies or to develop novel anti-SARS-CoV-2 antibody formats (Garner-Spitzer et al., 2021; Kallolimath et al., 2021; Sun et al., 2021). The availability of viral proteins in high quality and sufficient amounts now allows investigating the biological and virologic basics of SARS-CoV-2 to understand the infection and propagation mechanisms, the virus distribution in the body, the docking of the virus, viral immune evasion, and the immune response mechanism of the human body in more detail. At an unprecedented speed, various laboratories worldwide are now focusing on this emerging pathogen and combining their expertise to investigate the new spike protein of this virus to reach one common goal: Understand the virus, and exploit its weaknesses for effective treatments and vaccines. The shared lessons from this pandemic will prepare us for future challenges.

\section{DATA AVAILABILITY STATEMENT}

The original contributions presented in the study are included in the article. Further inquiries can be directed to the corresponding author.

\section{AUTHOR CONTRIBUTIONS}

$\mathrm{PM}, \mathrm{MH}$, and $\mathrm{RK}$ contributed to the conception and design of the study. PM wrote the first draft of the manuscript. All authors contributed to manuscript revision, read, and approved the submitted version.

\section{ACKNOWLEDGMENTS}

We thank Prof. Hannes Stockinger and Prof. Ursula Wiedermann-Schmidt (Medical University Vienna) for providing selected COVID positive sera for serological ELISA 
testing. We thank Dr. Thomas Kreil (Takeda) for providing SarsCoV-2 hyperimmune sera. We thank Dr. Miriam Klausberger, Dr. Mark Dürkop (both BOKU University Vienna), and the

\section{REFERENCES}

Allen, J. D., Chawla, H., Samsudin, F., Zuzic, L., Shivgan, A. T., Watanabe, Y., et al. (2021). Site-Specific Steric Control of SARS-CoV-2 Spike Glycosylation. Biochemistry 60, 2153-2169. doi:10.1021/acs.biochem.1c00279

Amanat, F., Stadlbauer, D., Strohmeier, S., Nguyen, T. H. O., Chromikova, V., McMahon, M., et al. (2020). A Serological Assay to Detect SARS-CoV-2 Seroconversion in Humans. Nat. Med. 26, 1033-1036. doi:10.1038/s41591020-0913-5

Bangaru, S., Ozorowski, G., Turner, H. L., Antanasijevic, A., Huang, D., Wang, X., et al. (2020). Structural Analysis of Full-Length SARS-CoV-2 Spike Protein from an Advanced Vaccine Candidate. Science 370, 1089-1094. doi:10.1126/ science.abe 1502

Budge, J. D., Young, R. J., and Smales, C. M. (2021). Engineering of Chinese Hamster Ovary Cells with NDPK-A to Enhance DNA Nuclear Delivery Combined with EBNA1 Plasmid Maintenance Gives Improved Exogenous Transient Reporter, $\mathrm{mAb}$ and SARS-CoV-2 Spike Protein Expression. Front. Bioeng. Biotechnol. 9, 679448. doi:10.3389/fbioe.2021.679448

Cai, Y., Zhang, J., Xiao, T., Peng, H., Sterling, S. M., Walsh, R. M., et al. (2020). Distinct Conformational States of SARS-CoV-2 Spike Protein. Science 369, 1586-1592. doi:10.1126/science.abd4251

Castro, R., Nobre, L. S., Eleutério, R. P., Thomaz, M., Pires, A., Monteiro, S. M., et al. (2021). Production of High-quality SARS-CoV-2 Antigens: Impact of Bioprocess and Storage on Glycosylation, Biophysical Attributes, and ELISA Serologic Tests Performance. Biotechnol. Bioeng. 118, 2202-2219. doi:10.1002/ bit. 27725

Chun, J., Cho, Y., Park, K. H., Choi, H., Cho, H., Lee, H.-J., et al. (2019). Effect of Fc Fusion on Folding and Immunogenicity of Middle East Respiratory Syndrome Coronavirus Spike Protein. J. Microbiol. Biotechnol. 29, 813-819. doi:10.4014/ jmb.1903.03043

Cibelli, N., Arias, G., Figur, M., Khayat, S., Leach, K., Loukinov, I., et al. (2021). Advances in Purification of SARS-CoV-2 Spike Ectodomain Protein Using High-Throughput Screening and Non-affinity Methods. Res. Sq. rs.3.rs-778537. doi:10.21203/rs.3.rs-778537/v1

Davidson, J. L., Wang, J., Maruthamuthu, M. K., Dextre, A., Pascual-Garrigos, A., Mohan, S., et al. (2021). A Paper-Based Colorimetric Molecular Test for SARSCoV-2 in Saliva. Biosens. Bioelectron. $X$ 9, 100076. doi:10.1016/ j.biosx.2021.100076

Esposito, D., Mehalko, J., Drew, M., Snead, K., Wall, V., Taylor, T., et al. (2020). Optimizing High-Yield Production of SARS-CoV-2 Soluble Spike Trimers for Serology Assays. Protein Expr. Purif. 174, 105686. doi:10.1016/ j.pep. 2020.105686

Farnós, O., Venereo-Sánchez, A., Xu, X., Chan, C., Dash, S., Chaabane, H., et al. (2020). Rapid High-Yield Production of Functional SARS-CoV-2 Receptor Binding Domain by Viral and Non-viral Transient Expression for Pre-clinical Evaluation. Vaccines 8, 654. doi:10.3390/ vaccines 8040654

Garner-Spitzer, E., Wagner, A., Kundi, M., Stockinger, H., Repic, A., Schoetta, A.M., et al. (2021). The Kinetic of SARS-CoV-2 Antibody (Ab) Decline Determines the Threshold for Ab Persistence up to one Year. medRxiv. doi:10.1101/2021.09.20.21263172

Henderson, R., Edwards, R. J., Mansouri, K., Janowska, K., Stalls, V., Gobeil, S. M. C., et al. (2020). Controlling the SARS-CoV-2 Spike Glycoprotein Conformation. Nat. Struct. Mol. Biol. 27, 925-933. doi:10.1038/s41594-0200479-4

Herrera, N. G., Morano, N. C., Celikgil, A., Georgiev, G. I., Malonis, R. J., Lee, J. H., et al. (2021). Characterization of the SARS-CoV-2 S Protein: Biophysical, Biochemical, Structural, and Antigenic Analysis. ACS Omega 6, 85-102. doi:10.1021/acsomega.0c03512

Hoffmann, D., Mereiter, S., Jin Oh, Y., Monteil, V., Elder, E., Zhu, R., et al. (2021). Identification of Lectin Receptors for Conserved SARS-CoV-2 Glycosylation Sites. EMBO J. 40, e108375. doi:10.15252/embj.2021108375
BOKU SARS-CoV2 initiative for fruitful discussions and exchange of equipment and reagents. Furthermore, we thank Dr. Gerhard Stadlmayr for SEC analyses.

Hsieh, C.-L., Goldsmith, J. A., Schaub, J. M., DiVenere, A. M., Kuo, H.-C., Javanmardi, K., et al. (2020). Structure-based Design of Prefusion-Stabilized SARS-CoV-2 Spikes. Science 369, 1501-1505. doi:10.1126/science.abd0826

Huang, Y., Yang, C., Xu, X.-f., Xu, W., and Liu, S.-w. (2020). Structural and Functional Properties of SARS-CoV-2 Spike Protein: Potential Antivirus Drug Development for COVID-19. Acta Pharmacol. Sin 41, 1141-1149. doi:10.1038/ s41401-020-0485-4

Johari, Y. B., Jaffé, S. R. P., Scarrott, J. M., Johnson, A. O., Mozzanino, T., Pohle, T. H., et al. (2021). Production of Trimeric SARS-CoV-2 Spike Protein by CHO Cells for Serological COVID-19 Testing. Biotechnol. Bioeng. 118, 1013-1021. doi:10.1002/bit.27615

Kallolimath, S., Sun, L., Palt, R., Stiasny, K., Mayrhofer, P., Gruber, C., et al. (2021). Highly Active Engineered IgG3 Antibodies against SARS-CoV-2. Proc. Natl. Acad. Sci. USA 118, e2107249118. doi:10.1073/pnas.2107249118

Kam, Y. W., Kien, F., Roberts, A., Cheung, Y. C., Lamirande, E. W., Vogel, L., et al. (2007). Antibodies against Trimeric S Glycoprotein Protect Hamsters against SARS-CoV challenge Despite Their Capacity to Mediate Fc $\gamma$ RII-dependent Entry into B Cells In Vitro. Vaccine 25, 729-740. doi:10.1016/ j.vaccine.2006.08.011

Kirchdoerfer, R. N., Wang, N., Pallesen, J., Wrapp, D., Turner, H. L., Cottrell, C. A., et al. (2018). Stabilized Coronavirus Spikes Are Resistant to Conformational Changes Induced by Receptor Recognition or Proteolysis. Sci. Rep. 8, 15701. doi:10.1038/s41598-018-34171-7

Li, J., Ulitzky, L., Silberstein, E., Taylor, D. R., and Viscidi, R. (2013). Immunogenicity and protection Efficacy of Monomeric and Trimeric Recombinant SARS Coronavirus Spike Protein Subunit Vaccine Candidates. Viral Immunol. 26, 126-132. doi:10.1089/vim.2012.0076

Mader, A., Prewein, B., Zboray, K., Casanova, E., and Kunert, R. (2012). Exploration of BAC versus Plasmid Expression Vectors in Recombinant CHO Cells. Appl. Microbiol. Biotechnol. 97, 4049-4054. doi:10.1007/s00253012-4498-x

Mayrhofer, P., and Kunert, R. (2020). "Screening of Media Supplements for HighPerformance Perfusion Cultures by Design of Experiment," in Animal Cell Biotechnology: Methods and Protocols Methods in Molecular Biology. Editor R. Pörtner (New York, NY: Springer US), 27-39. doi:10.1007/978-1-0716-0191-4 3

Meier, S., Güthe, S., Kiefhaber, T., and Grzesiek, S. (2004). Foldon, the Natural Trimerization Domain of T4 Fibritin, Dissociates into a Monomeric A-state Form containing a Stable $\beta$-Hairpin: Atomic Details of Trimer Dissociation and Local $\beta$-Hairpin Stability from Residual Dipolar Couplings. J. Mol. Biol. 344 (4), 1051-1069. doi:10.1016/j.jmb.2004.09.079

Reinhart, D., Damjanovic, L., Kaisermayer, C., Sommeregger, W., Gili, A., Gasselhuber, B., et al. (2018). Bioprocessing of Recombinant CHO-K1, CHO-DG44, and CHO-S: CHO Expression Hosts Favor Either mAb Production or Biomass Synthesis. Biotechnol. J. 14, 1700686. doi:10.1002/ biot. 201700686

Riguero, V., Clifford, R., Dawley, M., Dickson, M., Gastfriend, B., Thompson, C. et al. (2020). Immobilized Metal Affinity Chromatography Optimization for Poly-Histidine Tagged Proteins. J. Chromatogr. A 1629, 461505. doi:10.1016/ j.chroma.2020.461505

Schaub, J. M., Chou, C.-W., Kuo, H.-C., Javanmardi, K., Hsieh, C.-L., Goldsmith, J., et al. (2021). Expression and Characterization of SARS-CoV-2 Spike Proteins. Nat. Protoc. 16, 5339-5356. doi:10.1038/s41596-021-00623-0

Shang, J., Wan, Y., Luo, C., Ye, G., Geng, Q., Auerbach, A., et al. (2020). Cell Entry Mechanisms of SARS-CoV-2. Proc. Natl. Acad. Sci. USA 117, 11727-11734. doi:10.1073/pnas.2003138117

Stadlbauer, D., Amanat, F., Chromikova, V., Jiang, K., Strohmeier, S., Arunkumar, G. A., et al. (2020). SARS-CoV-2 Seroconversion in Humans: A Detailed Protocol for a Serological Assay, Antigen Production, and Test Setup. Curr. Protoc. Microbiol. 57, e100. doi:10.1002/cpmc.100

Stuible, M., Gervais, C., Lord-Dufour, S., Perret, S., L’Abbé, D., Schrag, J., et al. (2021). Rapid, High-Yield Production of Full-Length SARS-CoV-2 Spike Ectodomain by Transient Gene Expression in CHO Cells. J. Biotechnol. 326, 21-27. doi:10.1016/j.jbiotec.2020.12.005 
Sun, L., Kallolimath, S., Palt, R., Stiasny, K., Mayrhofer, P., Maresch, D., et al. (2021). Increased In Vitro Neutralizing Activity of SARS-CoV-2 IgA1 Dimers Compared to Monomers and IgG. Proc. Natl. Acad. Sci. USA 118, e2107148118. doi:10.1073/pnas.2107148118

Tian, W., Li, D., Zhang, N., Bai, G., Yuan, K., Xiao, H., et al. (2021). O-glycosylation Pattern of the SARS-CoV-2 Spike Protein Reveals an "O-Follow-N" Rule. Cell Res 31, 1123-1125. doi:10.1038/s41422-021-00545-2

Tian, X., Li, C., Huang, A., Xia, S., Lu, S., Shi, Z., et al. (2020). Potent Binding of 2019 Novel Coronavirus Spike Protein by a SARS Coronavirus-specific Human Monoclonal Antibody. Emerging Microbes \& Infections 9, 382-385. doi:10.1080/22221751.2020.1729069

Tortorici, M. A., Walls, A. C., Lang, Y., Wang, C., Li, Z., Koerhuis, D., et al. (2019). Structural Basis for Human Coronavirus Attachment to Sialic Acid Receptors. Nat. Struct. Mol. Biol. 26, 481-489. doi:10.1038/s41594-0190233-y

van den Brink, E. N., Ter Meulen, J., Cox, F., Jongeneelen, M. A. C., Thijsse, A., Throsby, M., et al. (2005). Molecular and Biological Characterization of Human Monoclonal Antibodies Binding to the Spike and Nucleocapsid Proteins of Severe Acute Respiratory Syndrome Coronavirus. J. Virol. 79, 1635-1644. doi:10.1128/JVI.79.3.1635-1644.2005

Walls, A. C., Park, Y.-J., Tortorici, M. A., Wall, A., McGuire, A. T., and Veesler, D. (2020). Structure, Function, and Antigenicity of the SARSCoV-2 Spike Glycoprotein. Cell 181, 281-292 e6. doi:10.1016/ j.cell.2020.02.058

Watanabe, Y., Allen, J. D., Wrapp, D., McLellan, J. S., and Crispin, M. (2020). Sitespecific Glycan Analysis of the SARS-CoV-2 Spike. Science 369, 330-333. doi:10.1126/science.abb9983

Wrapp, D., Wang, N., Corbett, K. S., Goldsmith, J. A., Hsieh, C.-L., Abiona, O., et al. (2020). Cryo-EM Structure of the 2019-nCoV Spike in the Prefusion Conformation. Science 367, 1260-1263. doi:10.1126/ science.abb2507
Wu, F., Zhao, S., Yu, B., Chen, Y. M., Wang, W., Song, Z. G., et al. (2020). A New Coronavirus Associated With Human Respiratory Disease in China. Nature 579, 265-269. doi:10.1038/s41586-020-2008-3

Xiong, X., Qu, K., Ciazynska, K. A., Hosmillo, M., Carter, A. P., Ebrahimi, S., et al. (2020). A Thermostable, Closed SARS-CoV-2 Spike Protein Trimer. Nat. Struct. Mol. Biol. 27, 934-941. doi:10.1038/s41594-020-0478-5

Yuan, M., Wu, N. C., Zhu, X., Lee, C.-C. D., So, R. T. Y., Lv, H., et al. (2020). A Highly Conserved Cryptic Epitope in the Receptor Binding Domains of SARSCoV-2 and SARS-CoV. Science 368, 630-633. doi:10.1126/science.abb7269

Zboray, K., Sommeregger, W., Bogner, E., Gili, A., Sterovsky, T., Fauland, K., et al. (2015). Heterologous Protein Production Using Euchromatin-Containing Expression Vectors in Mammalian Cells. Nucleic Acids Res. 43, e102. doi:10.1093/nar/gkv475

Conflict of Interest: The authors declare that the research was conducted in the absence of any commercial or financial relationships that could be construed as a potential conflict of interest.

Publisher's Note: All claims expressed in this article are solely those of the authors and do not necessarily represent those of their affiliated organizations, or those of the publisher, the editors, and the reviewers. Any product that may be evaluated in this article, or claim that may be made by its manufacturer, is not guaranteed or endorsed by the publisher.

Copyright (c) 2021 Mayrhofer, Hunjadi and Kunert. This is an open-access article distributed under the terms of the Creative Commons Attribution License (CC BY). The use, distribution or reproduction in other forums is permitted, provided the original author(s) and the copyright owner(s) are credited and that the original publication in this journal is cited, in accordance with accepted academic practice. No use, distribution or reproduction is permitted which does not comply with these terms. 